\title{
BioéthiqueOnline
}

\section{Managing Profound Suffering at the End-of-Life: Should expanding access to continuous deep sedation be the priority?}

\section{Jeffrey Kirby}

Volume 4, 2015

Reçu : 10 Nov 2014; publié : 30 Jan 2015; éditeurs : Hadi Karsoho \& Lise Lévesque

URI : https://id.erudit.org/iderudit/1035489ar

DOI : https://doi.org/10.7202/1035489ar

Aller au sommaire du numéro

Éditeur(s)

BioéthiqueOnline

ISSN

1923-2799 (numérique)

Découvrir la revue

Citer cet article

Kirby, J. (2015). Managing Profound Suffering at the End-of-Life: Should expanding access to continuous deep sedation be the priority?

BioéthiqueOnline, 4. https://doi.org/10.7202/1035489ar
Résumé de l'article

En ce qui concerne le traitement et la gestion de la souffrance profonde à la fin de la vie, cet article soutient que la priorité ne devrait pas être la légalisation de l'aide médicale au suicide ou celle de l'euthanasie active et volontaire là où ces pratiques ne sont pas actuellement disponibles. Plutôt, les professionnels de la santé et la société devraient faire des efforts concertés afin d'accroître l'accès des patients à de la sédation proportionnelle pour soulager leur détresse et à de la sédation profonde continue. 


\title{
Managing Profound Suffering at the End-of-Life: Should expanding access to continuous deep sedation be the priority?
}

\author{
COMMENTAIRE / COMMENTARY \\ Jeffrey Kirby, MA, MD ${ }^{1}$
}

Reçu/Received: 10 Nov 2014

Éditeurs/Editors: Hadi Karsoho \& Lise Lévesque

Publié/Published: 30 Jan 2015

2015 J Kirby, Creative Commons Attribution 4.0 International License

\begin{abstract}
Résumé
En ce qui concerne le traitement et la gestion de la souffrance profonde à la fin de la vie, cet article soutient que la priorité ne devrait pas être la légalisation de l'aide médicale au suicide ou celle de l'euthanasie active et volontaire là où ces pratiques ne sont pas actuellement disponibles. Plutôt, les professionnels de la santé et la société devraient faire des efforts concertés afin d'accroître l'accès des patients à de la sédation proportionnelle pour soulager leur détresse et à de la sédation profonde continue.
\end{abstract}

\section{Mots clés}

assistance médicale à mourir, souffrance profonde, sédation continue, euthanasie, suicide assisté

\section{Summary}

This paper argues that in addressing and managing profound suffering at the end-of-life, the priority should not be the legalization of physician-assisted suicide or voluntary active euthanasia in jurisdictions where these practices are not currently available. Rather, concerted efforts should be made by society and the healthcare provider community to expand patient access to proportionate distress-relieving sedation and continuous deep sedation.

\section{Keywords}

medical aid in dying, profound suffering, continuous deep sedation, euthanasia, assisted suicide

Affiliations des auteurs / Author Affiliations

${ }^{1}$ Professor, Department of Bioethics, Faculty of Medicine, Dalhousie University, Halifax, Nova Scotia, Canada

\section{Correspondance / Correspondence}

Dr. Jeffrey Kirby, jeffrey.kirby@dal.ca

Conflit d'intérêts

Aucun déclaré
Conflicts of Interest

None to declare

\section{Introduction}

The recent passing of Bill 52 in the Canadian province of Quebec, which provides a legislative framework for the practice of voluntary active euthanasia (VAE), has added some fresh kindling to the provocative fires of debate and controversy about three assisted death practices: continuous deep sedation (CDS), physician-assisted suicide (PAS) and voluntary active euthanasia [1]. In my view, the priority of the healthcare provider community and society in addressing profound suffering at the endof-life in North American jurisdictions without legalized PAS should be concerted efforts to expand the access of patients to CDS and proportionate distress-relieving sedation. In arguing for the privileging of this approach over the legalization of PAS and VAE, there is no need to cast moral aspersions on either of these practices.

I begin by describing the relevant distinctions between two sets of health-related, assisted dying circumstances that are underappreciated in the academic literature and lay media. I then provide relevant details of the prioritized approach for which I am advocating, i.e., expanded access to sedation. Subsequently, through a comparative analysis of this approach and the legalization of PAS/VAE, I explore and uncover a set of advantages of the former approach over the latter in terms of potential relief of the profound suffering of patients at the end-of-life. 


\section{Two Distinct Sets of Assisted Dying Circumstances}

There are two sets of health-related circumstances in which assisted dying practices can potentially be used to manage the suffering of patients. The first, and by far the most common, is the set of circumstances that are considered to constitute paradigm indications for the use of CDS, PAS and VAE [2]. These clinical scenarios are characterized by profound suffering - typically consisting of commingled and intersecting physical and psycho-existential distress elements $[3,4]$ - that is experienced by patients as unbearable [5]. In such circumstances, the patient's suffering has proven refractory to an array of acute and palliative care treatment modalities (including, in some cases, the use of proportionate distress-relieving sedation) in the context of anticipated 'near' death, i.e., attending healthcare providers estimate that death will occur within days to a few weeks.

The description of the associated required element of refractoriness in national Dutch guidelines is as good as any: when available treatment modalities have failed, or it is anticipated that they will either not be successful or are likely to result in more burdens than benefits, or when the capable patient has made an informed decision to forgo further possible treatment [6]. Initiation of CDS, i.e., the intentional induction and continuous maintenance of a coma-like level of sedation until death, requires either the direct consent of the capable patient or the indirect consent of the legally-designated substitute decision maker(s), who is usually a family member(s) [7]. Once CDS has been achieved, nutrition and hydration are usually discontinued, given the lack of rationale for their continued use in this context $[5,8,9]$. For patients whose death is estimated by their attending physicians to be 'near', the median time interval from initiation of CDS until death is one to four days $[5,8]$.

The second set of health-related circumstances in which requests for PAS/VAE are sometimes made occurs much less frequently. In these non-paradigm circumstances, which have been described as "agent-narrative suffering" [10] scenarios, a capable person whose death is not anticipated to be 'near' requests assistance in dying because of the presence of a significant health condition that, from her/his perspective, makes the prospect of further life 'not worth living' because of one or more person-specific quality-of-life factors, e.g., inability to participate in activities that formerly made life meaningful or enjoyable; hopelessness; perception of progressive loss of 'self', dignity and/or independence; a preference for control over one's destiny; not wishing to become a burden to loved ones [3,11]. Typically, individuals who wish to prematurely end their lives in these circumstances are highly actualized in educational, occupational and economic domains [3,12].

At the present time, individuals in these non-paradigm circumstances whose survival is anticipated to be more than six months do not have access to any of the assisted dying practices in North American jurisdictions, and the potential implementation of Bill 52 is unlikely to change this in Quebec, given that it contains a legislative requirement for the presence of "an advanced state of irreversible decline in capability" [1]. The current reluctance to de-link assisted dying practices to the presence of terminal health-states in North America seems to be well-entrenched, and this reluctance has likely been fortified in the public eye by critical responses to reports out of Belgium in recent years about the euthanizing (or planned euthanization) of a person with anorexia nervosa, middle-aged twins with congenital deafness who were progressively losing their sight due to glaucoma, a transgendered person and an incarcerated murderer-rapist. The access of individuals living in England and Wales who are in non-paradigm circumstances to an assisted death has arguably been enhanced by a stateinstituted, pragmatic work-around: in 2010, the Director of Public Prosecutions disclosed a set of six mitigating factors, including direct-explicit consent, motivation by compassion and open-reporting to police, that, if present, are unlikely to lead to criminal prosecution of those who 'reluctantly' assist individuals to die (as long as, as subsequently amended, they have not been direct healthcare providers of the assisted person) [13]. This non-legislative approach is a possible, expedient option for North American jurisdictions where it is unlikely that assisted death practices will be legalized for other than 'near-death' clinical circumstances. 


\section{Expanded Access to Continuous Deep Sedation}

At the present time, access to CDS is quite limited in North America and there are particular deficiencies in rural and other medically under-resourced settings. The Canadian Senate's 2005 Still Not There, Quality End-of-Life Care Progress Report estimated that only 5\% of Canadians have access to integrated palliative care including proportionate distress-relieving sedation and CDS, and that the percentage for those who reside in rural and remote areas is even lower [14]. The Ontario Health Technology Advisory Committee End-of-Life Collaborative reported in December 2014 that $70 \%$ of Canadians with advanced chronic illness, the underlying cause of most deaths, do not have access to formal end-of-life care [15]. In terms of the need for relief of terminal suffering through the use of an assisted death practice such as CDS, Timothy Quill and Robert Brody have indicated that, in their experience, $2 \%$ of patients have unacceptable relief of their pain-related distress at the end of life [16]. A 2007 study revealed that, of a cohort of patients who were actively-living with terminal cancer, $6 \%$ would request the use of an assisted death practice in their current circumstances if one was accessible to them [17].

In North American settings, CDS is primarily prescribed by urban-based palliative medicine specialists and administered to patients who are hospitalized in specialized palliative care units [18]. The accessibility of patients in near-death paradigm circumstances to CDS needs to be significantly improved. Enhancement of the existing capacities of family physicians to prescribe and direct the administration of this palliative care practice is required. With this goal in mind, the primary education of medical students/residents and the continuing professional development of practicing family physicians should include comprehensive training in the delivery of integrated palliative care, including CDS and proportionate distress-relieving sedation [8].

The current lack of competency of most North American family physicians to offer CDS as a component of integrated palliative care is due to a lack of training in assessing one element of the paradigm indications, and a corresponding lack of experience in prescribing and monitoring the practice. In terms of traditionally-acquired knowledge and skills, family physicians with practice experience are typically able to recognize/appreciate when their patients are experiencing profound suffering, and when their death is likely to occur within days to a few weeks. However, enhanced training is necessary to assist family physicians in their development of the knowledge and confidence to discern when their patient's intolerable distress should be considered refractory. In addition to targeted education and professional development, an optimal supplementary mechanism to help achieve this objective would be to establish jurisdiction-wide networks of palliative medicine specialists who support the expanded access of patients to integrated palliative care and are willing to provide telephone (or videoconference, as available) support to family physicians while they are building their practice capacities in this regard.

Once CDS is requested by a patient or substitute decision maker who has been pre-informed of the full scope of possible palliative care interventions, the practical administration of sedating agents is relatively uncomplicated; in most cases, a benzodiazepine such as midazolam is administered by nurses (or trained family members) via continuous subcutaneous infusion sets in hospital, hospice or home settings [5]. (Approximately $80 \%$ percent of the CDS provided in the Netherlands is administered at home, and home-based CDS is a common occurrence in the UK [20].) Other than monitoring the level of achieved sedation, managing uncommon side effects, and infrequently changing subcutaneous infusion sites, nothing else of a complicated or technical nature needs to be performed in most circumstances. In clinical scenarios characterized by co-morbid terminal delirium and/or dyspnea that has not responded adequately to administration of a benzodiazepine, firstgeneration antipsychotic agents, such as levomepromazine and haloperidol, can be added to the subcutaneous treatment regime $[5,21]$. 


\section{Advantages of an Expanded Access to CDS Approach over Legalization of PAS/VAE}

There are a number of advantages to an 'expanded access to CDS' approach over legalization of PAS/VAE in near-death paradigm circumstances in the sense of potential relief of the profound suffering of more patients. These advantages are described below under the categories of: buy-in considerations, a key difference in consent procedures, a distinction in the obligations to meet healthcare needs, and resource allocation considerations.

\section{Buy-in Considerations}

Unlike PAS and VAE, CDS is considered by palliative medicine specialists to fall within the scope of integrated palliative care, and CDS practice is reflected as such in the advisory guidelines of many national palliative medicine societies and associations [4,8,20,21]. Although I do not personally see/recognize a clear moral distinction between CDS and PAS/VAE, most palliative medicine specialists, family physicians and other healthcare providers do view CDS as distinct from, and less morally problematic than, PAS/VAE [18]. The doctrine of double effect is thought by most palliative medicine specialists and other physicians to extend to CDS (as opposed to PAS/VAE), i.e., it is morally permissible for doctors to provide CDS in near-death paradigm circumstances if the physician's sole intention is to relieve suffering, even though the theoretically 'bad effects' of unconsciousness and minimal hastening of death are definitely foreseen in the former and possible in the latter (in the absence of matched cohort date, there remains no definitive answer to the question of whether CDS minimally hastens death, although it's fair to claim that the use of CDS does not knowingly hasten death) [4,5]. This doctrine, derived from Roman Catholic moral theology and influenced by Kantian ethics, is usually cited as the primary theoretical justification for CDS by its proponents, despite recent academic/analytic work that has demonstrated the conceptual and psychological complexity of human intentions in this context, where motivations are ambiguous in nature and difficult to evaluate $[4,18,21]$.

Those who recognize and value intention-based distinctions, as do most physicians, are more likely to buy into the enhanced access of patients in rural and other medically under-resourced settings to CDS than they are to: 1) support the legalization of PAS and/or VAE, and 2) participate in either of these latter practices. Another 'buy-in' advantage of CDS over VAE is that only the former practice allows for some perceived diffusion of professional responsibility for the actions taken; the sedative agent used in CDS is ordered by the attending physician and typically administered by a cohort of nurses (and/or family members in the home setting) while, in VAE, the participating physician orders (decides to administer) and, in most cases, subsequently directly injects a 'lethal cocktail' [19].

\section{A Key Difference in Consent Procedures}

Another important and under-appreciated distinction between CDS and PAS/VAE and an important, pragmatic advantage of CDS over the latter two practices, in the particular sense articulated above, relates to a difference in the standard consent procedures associated with these practices. In countries and jurisdictions in which PAS and/or VAE are legal, legislatively-based regulations require the direct consent of a capable patient [22]. However, in near-death paradigm circumstances, the capacity of patients to make their own end-of-life decisions is frequently compromised [7,12]. For those patients whose profound suffering, terminal state, and lack of further viable treatment options is first demonstrated in critical care settings, over ninety percent lack the capacity to make end-of-life decisions for themselves [23]. In reality, for the majority of patients in near-death paradigm circumstances in countries with and without legalized PAS and/or VAE, the only available option to relieve the patient's profound suffering is CDS that has been consented-to by a family member (or other substitute decision maker).

Proponents of legalized PAS/VAE could argue that this particular advantage (in terms of the access of more patients to relief of their unbearable suffering) could be eliminated by revising current PAS/VAE practices to allow for indirect consent. However, such a change in legislation and practice would 
require social consensus support in North American jurisdictions, which is unlikely to be achieved on a political level given prevailing fears and worries about intra-familial victimization and discrimination against differently-abled persons. So, for the time being at least, the profound suffering of a greater number of patients in near-death paradigm circumstances, i.e., those with and without capacity, could potentially be effectively relieved by CDS than by legalized PAS/VAE, as the latter practices can only be administered to the minority of patients who have retained their capacity to make healthcare decisions in these circumstances. Characterizing this as an advantage of the 'enhanced access to CDS' approach is not to suggest or claim that CDS is morally superior to legalized PAS/VAE on the sole basis of how the principle of respect for individual autonomy is differently-actualized in these practices.

\section{A Potential Distinction in the Obligations to Meet Healthcare Needs}

Beyond simple utility calculations, e.g., "there are more persons with profound distress in near-death paradigm circumstances than persons seeking medically-assisted dying in non-paradigm circumstances", an 'obligations to meet healthcare needs' argument could possibly support the prioritization of expanded access to CDS over the legalization of PAS/VAE. As indicated above, CDS is the only assisted death practice that can meet the needs of the majority of patients in near-death paradigm circumstances, while only legalized PAS or VAE can meet the needs of those in nonparadigm circumstances, given the fixed CDS-related requirement for patients to be within a few weeks of death. The healthcare needs of persons who are experiencing unbearable suffering at the end-of-life are typically considered to be of high magnitude. Intense suffering typically engenders a strong obligation on the part of healthcare providers (and society) to address such distress on a priority basis.

The healthcare needs of individuals in non-paradigm circumstances include relief of existing distress and management of their underlying health condition(s). Given the previously-described motivations of persons who request PAS/VAE, the distress experienced by individuals in these circumstances tends to be primarily psycho-existential in nature, i.e., it is connected to, and constituted by, perceived (current or future) loss of valued self-identity and self-agency. Although, various types and forms of suffering are difficult to describe, quantify and compare, the active degree of suffering and related magnitude of healthcare need in relevant case histories are typically lower for most individuals in nonparadigm circumstances than for most in near-death paradigm circumstances [3,11]. This apparent differential in degree of healthcare need could conceivably give rise to a greater obligation to address the needs of individuals in the latter circumstances than to address the needs of those in the former, and provide a possible justification for prioritizing an 'expanded access to CDS' approach over the legalization of PAS/VAE in jurisdictions where one of the latter practices is not available.

\section{Resource Allocation Considerations}

From a 'fair allocation of limited health resources' perspective, another potential advantage of expanded access to CDS is that this approach is likely to be less costly to challenged, publicly-funded healthcare systems than the setting-up and continuous maintenance of expert- and staff-dependent commissions and formal regulatory mechanisms to monitor the legalized practices of PAS or VAE. Further, improving the access of patients in near-death paradigm circumstances to the already legal and accepted palliative care practice of CDS does not require the costly political advocacy and lawchallenging efforts that are necessary to make PAS or VAE options in countries and jurisdictions where they are not currently legalized. There would, of course, be some initial costs associated with expanding the access of patients to CDS in North American jurisdictions, i.e., those expenses associated with enhancement of the curricula of medical schools and the remuneration of palliative medicine specialists who are engaged in capacity-building networks. In terms of financial considerations related to direct bedside care in near-death paradigm circumstances, there is likely 'to be a wash' between the costs associated with caring for patients at home for several-day periods of CDS and the expenses associated with delays in obtaining formal second opinions and in completing documentation that is required by PAS and VAE regulatory systems. 


\section{Conclusion}

Although expanding the access of patients in near-death paradigm circumstances to CDS does not provide the distress-relief sought by individuals in non-paradigm circumstances, it does have the capacity to effectively manage the profound suffering of most patients at the end-of-life. Given the advantages of this approach over the legalization of PAS/VAE, in my view, concerted efforts to expand the access of patients to CDS should be prioritized over legalization efforts in North American jurisdictions where PAS/ or VAE is not already available or legislatively-approved.

\section{References}

1. National Assembly of the Province of Quebec: Bill 52: An Act Respecting End-of-Life Care, 2014.

2. Swart SJ, van der Heide A, van Zulen L, et al. Continuous palliative sedation: Not only a response to physical suffering. Journal of Palliative Medicine 2014;17(1):27-36.

3. Dees MK, Vernooij-Dassen MJ, and Vissers KC. 'Unbearable suffering': A qualitative study on the perspectives of patients who request assistance in dying. Journal of Medical Ethics 2011;37:727-34.

4. Rys S, Deschepper R, Mortier F, et al. The moral difference or equivalence between continuous sedation until death and physician-assisted death: Word games or war games. Journal of Bioethical Inquiry 2012;9:171-83.

5. de Graeff A, Dean M. Palliative sedation therapy in the last weeks of life: A literature review and recommendations for standards. Journal of Palliative Medicine 2007;10(1):67-85.

6. Royal Dutch Medical Society: RDMS Guideline Palliative Sedation, 2005.

7. Raus K, Anquinet L, Rietjens J, et al. Factors that facilitate or constrain the use of continuous sedation at the end of life by physicians and nurses in Belgium: Results from a focus group study. Journal of Medical Ethics 2014;40:230-34.

8. Chambaere K, Bilsen J, Cohen J, et al. Continuous deep sedation until death in Belgium: A nationwide survey. Archives of Internal Medicine 2010;170(5):490-93.

9. Rietjens JAC, Onwuteaka-Philipsen BD, van Delden JJM, et al. Two decades of research on euthanasia from the Netherlands: What have we learnt and what questions remain? Journal of Bioethical Inquiry 2009;6:271-83.

10. Jansen LA, and Sulmasy DP. Proportionality, terminal suffering and the restorative goals of medicine. Theoretical Medicine 2002;23:321-37,324

11. Shildrick M. Deciding on death: Conventions and contestations in the context of disability. Journal of Bioethical Inquiry 2008;5(2):209-19.

12. Battin MP, van der Heide A, Ganzini L, et al. Legal physician-assisted dying in Oregon and the Netherlands: Evidence concerning the impact on patients in "vulnerable" groups. Journal of Medical Ethics 2007;33:591-97.

13. The Crown Prosecution Service. Assisted Suicide: Prosecution policy and guidance.

14. Carstairs, S. Still Not There Quality End-of-Life Care: A Progress Report. 2005.

15. Sikich N, and Ontario Health Technology Advisory Committee End-of-Life Collaborative, Health Quality Ontario. Health care for people approaching the end of life: An evidentiary framework. 2014.

16. Quill TE, and Brody RV. 'You promised me I wouldn't die like this!': A bad death as a medical emergency. Archives of Internal Medicine 1995;155:1250-54.

17. Wilson KG, Chochinov HM, McPherson CJ, et al. Desired for euthanasia or physician-assisted suicide in palliative cancer care. Health and Psychology 2007:26(3):314-23.

18. Lo B, and Rubenfeld G. Palliative sedation in dying patients: "We turn to it when everything else hasn't worked". Journal of the American Medical Association 2005;294(14):1810-16.

19. Raus K, Sterckx S, and Mortier F. Continuous deep sedation at the end of life and the "natural death" hypothesis. Bioethics 2012;26(6):329-36.

20. Dean MM, Cellarius V, Henry B, et al. Framework for continuous palliative sedation therapy in Canada. Journal of Palliative Medicine 2012;5(8):870-76. 
21. Quill TE, Dresser R, Brock DW. The rule of double effect - A critique of its role in end-of-life decision making. The New England Journal of Medicine 1997;337(24):1768-71.

22. Periera J. Legalizing euthanasia or assisted suicide: The illusion of safeguards and controls. Current Oncology 2011;18(2):e38-45.

23. Carlet J, Thijs LF, Antonelli M. Statement of the fifth international consensus conference in critical care: Challenges in end-of-life care in the ICU. Intensive Care Medicine 2003;30:77084. 